\title{
Acoustic Signal Processing for Seabed Layer Identification
}

\author{
V. Sunanthini, Gunaselvi Manohar, R. Sudha, Pearley Stanley, Lakshmi R
}

\begin{abstract}
In this critique, chirp sonar signals are processed to classify the bottom sediments. Composed sonar data are sorted and reported. Reproduced and imitated data obtained by sonar parametric analysis is done for target categorization. This paper presents the functions of the duration made by echoes are qualified and separated. Hilbert transform is related with the spreader resound signals to estimate the degree of the underneath desire reactions.
\end{abstract}

Keywords : Seabed categorization, Hilbert Transforms chirp signals, Beam Echo Sounders (SBES), Echo duration

\section{INTRODUCTION}

Based on unique responses from ocean floors, the arrangement of seafloor into marine remains of varieties and groups. Precise marine classification is crucial in oceanic behaviors like ocean geology, industrial fishing, wire and conduit construction. The physical nature of the marine sonar echoes (resound indications) is vital for knowing the validation of modes applied for different underwater activities like seabed categorization .The interaction of sonar signal with the seafloor is more convoluted than that its networking of marine surfaces. Its dependence on frequency in certain methods makes the loss due to the creeping of energy into layers.. Low frequency signal can be absorbed by sediments and produce internal reflections .According to the wavelength $(\lambda=\mathrm{c} / \mathrm{f})$, where $\mathrm{c}$ is the $\mathrm{f}$ is the frequency and $\mathrm{c}$ is the sound velocity in water, less penetration happens at high frequency into the remains of layers. The frequency of chirp signal indicates a sine wave which varies at a linear rate with time. The instantaneous frequency $f(t)$ increases with time: $f(t)=f_{0}+\mathrm{kt}$ where $f_{0}$ is the starting frequency (at time $t=0$ ), and $k$ is the chirp rate or increase in frequency. The time-domain function for a linear chirp with sinusoidal signal is

$$
\begin{gathered}
x(t)=\sin \left[2 \pi \int_{0}^{t} f\left(t^{\prime}\right) d t^{\prime}\right]=\sin \left[2 \pi \int_{0}^{t}\left(f_{0}+k t^{\prime}\right) d t^{\prime}\right] \\
\mathrm{x}(\mathrm{t})=\sin \left[2 \pi\left(f_{0}+\frac{k}{2} t\right) t\right]
\end{gathered}
$$

Revised Manuscript Received on 14 September, 2019.

V Sunanthini, is with the Department of Electronics and Instrumentation Engineering, Easwari Engineering College, Tamil Nadu, India .

Gunaselvi Manohar, is with the Department of Electronics and Instrumentation Engineering, Easwari Engineering College, Tamil Nadu, India.

Sudha R, is with the Department of Electronics and Instrumentation Engineering, Easwari Engineering College, Tamil Nadu, India.

Pearley Stanley, is with the Department of Electronics and Instrumentation Engineering, Easwari Engineering College, Tamil Nadu, India (E-mail:pearleysolace@gmail.com).

Lakshmi R, is with the Department of Electronics and Instrumentation Engineering, Easwari Engineering College, Tamil Nadu, India .

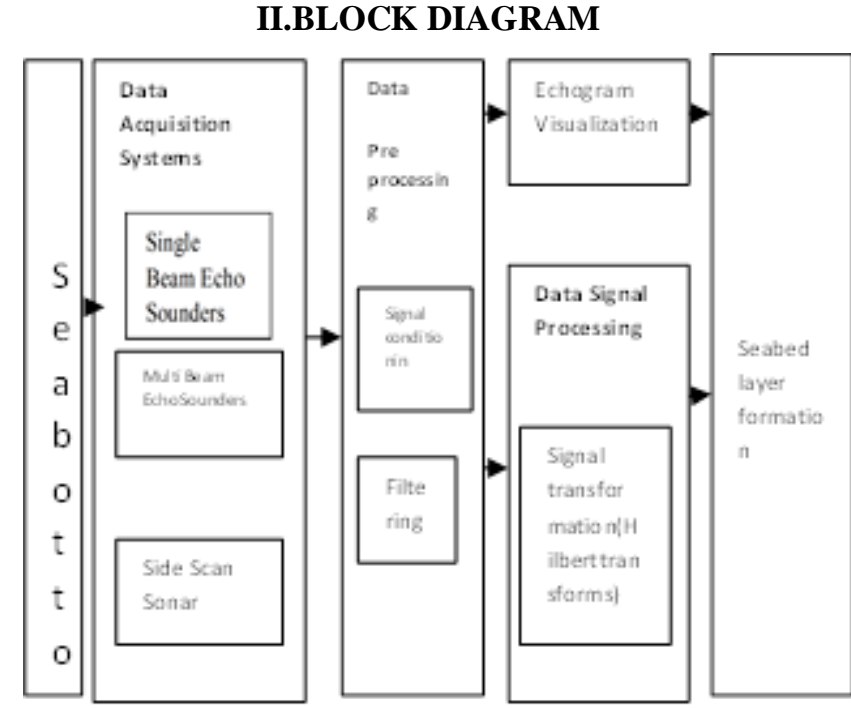

Fig.1.Geo Acoustic model for seabed classification

The chirp rate is the rate of frequency modified .The binary data is communicated by recording opposite chirp rates in binary modulation. "1" is given a chirp with positive rate $a$ and " 0 " is a chirp with negative rate -a over one bit period. In marine applications, chirps are used with superior sources for communication. The received linear chirps are available with harmonic filters. The central frequency is brushed and processed with signal processing across the range of frequencies $2 \mathrm{kHz}$ to $9 \mathrm{kHz}$ and can increase the precision near seabed remains. The signal of $2 \mathrm{kHz}$ is taken as starting frequency. The time at which the frequency reaches the target is the target time its parameter value is 20 milliseconds. The frequency of the signal at the target time is $9 \mathrm{kHz}$.

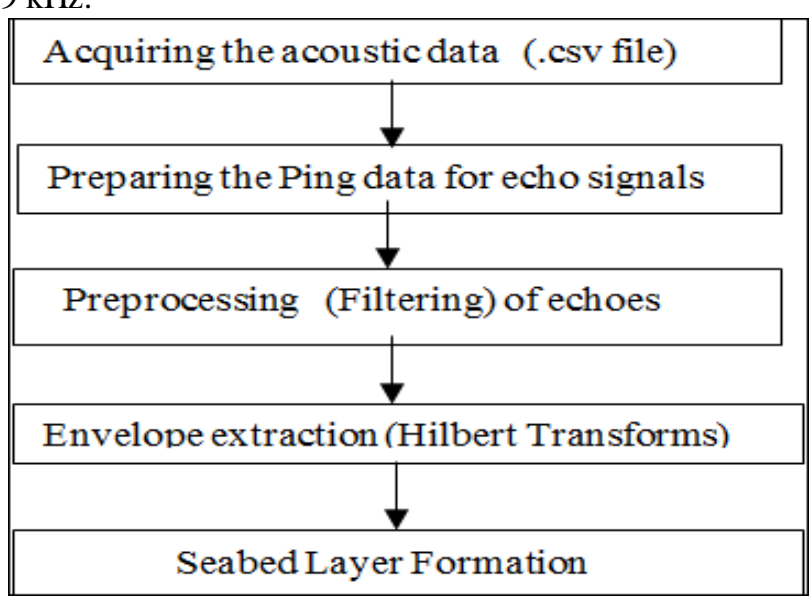

Fig.2. Flow chart for seabed classification 


\section{ACQUIRING AND PREPARING ACOUSTIC DATA}

The pulse is converted into electric signal and communicated as transmit pulse. The same transducer then receives the echo, which includes signal (backscatter information) and sound . The above information is available as .csv file format. During the transmit/receive cycle(ping), a communication switch is provided with proper connections .

To explain the results of collected data, feature, and show, it is needed to understand the reproduction of signals from layers . A monocratic reflections and sounds dependent on replica of the scattered chirp frequencies of $2 \mathrm{kHz}-9 \mathrm{kHz}$. Scattering at high frequency from the seabed is reported as the coarseness of the Interface of seabed and water, the unevenness of the interfaces between the layers of seabed, pulses of scatters within the seabed and rises and falls in the sound frequency and density related to volume.

In softer, fine textured soils (i.e., muds and silts) , low reflections are reported. Rougher substrates like well drained sandy soils, tendency of high reflectance is caused . Stronger echoes will result from a hard seabed such as rock. Weak echoes will be received from softer materials such as sand or mud. When high-frequency pulse backscatters from seabed, the occurrence of frequency shifts. The segmentation of seabed into varying ranks of diversity are provided by SBES. systems Acoustically soft to hard and smooth to coarse seabed are well defined.


Fig.3.Single beam echo sounder echogram

To determine echo durations from these echo-envelope time

Series, both the start and end of each echo must be identified, commonly called picking. The duration of each echo is plotted against its altitude as measured from its startof-echo pick.

\section{PREPROCESSING OF ECHO SIGNALS}

The collected echo or Ping data course is filtered. The band pass FIR filter is used to remove high frequency elements with band frequencies in out of portion. The smooth resultant echo signal can be stored and shown as an echogram. This serves as the raw data for remains categorization of seabed layers..

In the sound separation, the depth of reflected echoes point out types of sediments. The shape and details of echogram makes indication different layers..

The FIR filter can be related as

$$
\mathrm{y}[\mathrm{n}]=\mathrm{x}[\mathrm{n}]+\mathrm{r} * \mathrm{x}[\mathrm{n}-\mathrm{P}]
$$

The echoes and reverberations can be produced by the delay terms in the formula of FIR filter. The ping data stream of $2 \mathrm{KHz}$ to $9 \mathrm{KHz}$ pass band FIR filter is designed for $50 \mathrm{KHz}$ sampling frequency and the output can be get as filtered output The filtered output should be the raw data for the signal transformation unit. Cascading of two FIR filters can make the restoration of an image. The method applied to obtain the waveform is deconvolution. .Each row or column of the image can be one dimensional signal with application of filtering.

\section{ENVELOPE EXTRACTION OF ACOUSTIC ECHOES}

\section{A. Hilbert Transforms (HT)}

The linear operator gets the function $f(t)$ and makes the function $f(t)$ with the identical field. It produces the specific features for reproducing harmonic conjugate of a the Fourier series. This tool makes a singular operator and a multiplier for derivation of a signal $f(t)$.

The derived function $\hat{f}(t)$ from $f(t)$ is represented as

$$
H(f(t))=\hat{f}(t)=\frac{1}{\pi} P \int_{-\infty}^{\infty} \frac{f(\tau)}{t-\tau} d \tau
$$

Hilbert transform could not be expressed as an irregular and normal integral due to the pole at $\mathrm{t}=\tau$. The expansion of the group relations for the integral gives the Cauchy principal value.

For even N, the discrete analogue of the Hilbert transform is implemented by

$$
\begin{gathered}
H(k)= \\
\begin{cases}-i \text { for } k=1,2, \ldots \ldots, \frac{N}{2}-1 \\
0 \quad \text { for } k=0 \text { and } \frac{N}{2} \\
i \quad \text { for } k=\frac{N}{2}+1 \ldots \ldots . N-2, N-1\end{cases}
\end{gathered}
$$

and $\mathrm{H}[\mathrm{k}]$ can be written on the form

$$
H(k)=-i \operatorname{sgn}\left(\frac{N}{2}-k\right) \operatorname{sgn}(k)
$$

The response in the time domain, for even $\mathrm{N}$ is given by

$$
\begin{aligned}
h(n) & =\frac{1}{N} \sum_{k=0}^{N-1} H[k] e^{i \frac{2 \pi}{N} k n} \\
& =\frac{1}{N} \sum_{k=0}^{N-1}-i \operatorname{sgn}\left(\frac{N}{2}-k\right) \operatorname{sgn}(k) e^{i \frac{2 \pi}{N}}=\frac{2}{N}
\end{aligned}
$$

$\sum_{k=1}^{\frac{N}{2}-1} \sin \left(\frac{2 \pi}{N} k n\right.$

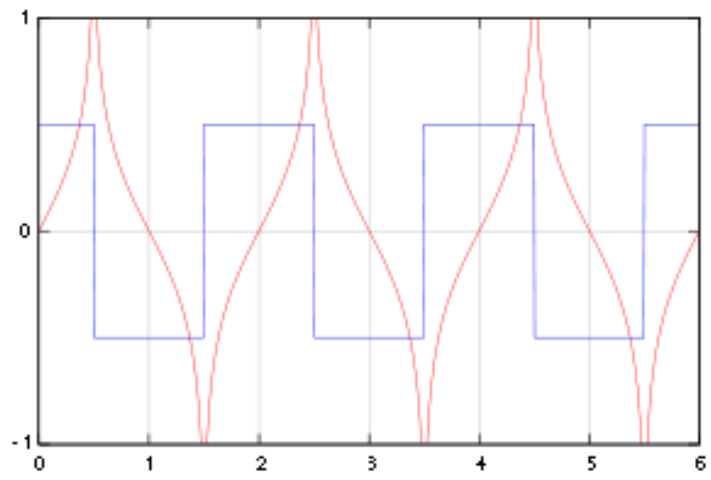

Fig.5.Hilbert transform of impulse

Applications for this operation include estimating the decay rate of an impulse in the time domain and the propagation time estimation. For the synthetic data, a signal should be measured at two points, the cross




correlation of those two measurements is made and then the Hilbert transform is used as shown in this example to find the envelope of the cross. For real sonar ping data, the filtered response is subjected to Hilbert transform and absolute value is calculated to get the envelope of the Sonar pings.

\section{B. Envelope Extraction Algorithm}

A general and effective way of envelope determination is produced Hilbert transform technique. It is specifically detected and phase shifted with original signals. The signal is delayed to interpret the group delay of Hilbert transform. The peak hold functions are executed with single pole IIR filter

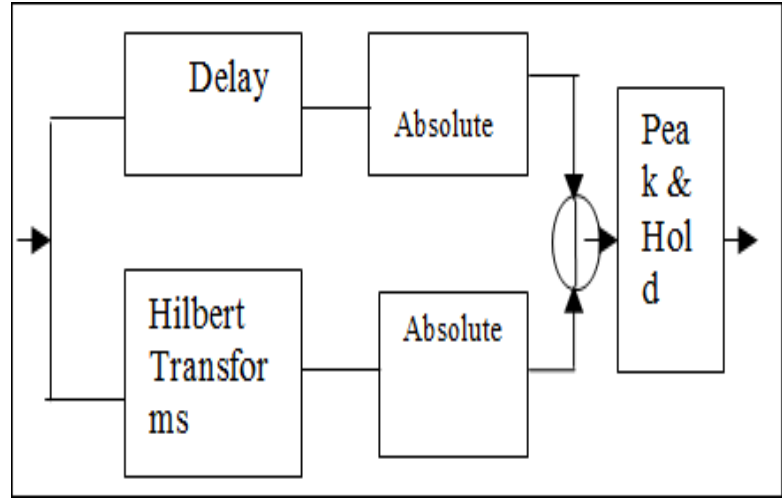

Fig.4. Schematic representation of Envelope extraction

\section{SEABED IMAGE FORMATION}

Resonant signal vs. depth from a coarse layers of seabed remains over a range of simulated roughness heights forms the plots of echo duration vs. depth made .In the exceptional case of zero roughness the backscatter is definitely specific spectrum. The effective beam width is zero, making the echo duration equal to the pulse length at all depths. As roughness increases, the effective beam width increases as more off-nadir surface facets are angled to backscatter energy.

Image processing tool box is used to form the seabed layer for the given real sonar data. From the plot of Echo duration Vs. Depth. The segregation effects of remains of seabed on resounds form the seabed layer image in colour map and in grayscale image

\section{RESULTS AND DISCUSSION}

Simulation in MATLAB can be achieved by examining the response of sonar signals for seabed classification, The received and retuned sound is termed ping data from sonar. The ping data are collected as .csv file and given as input. From the ping data stream the following parameters are identified as

Sampling period $=20$ microseconds

Echo duration $=12500 * 20$ microseconds $=0.25$ seconds;
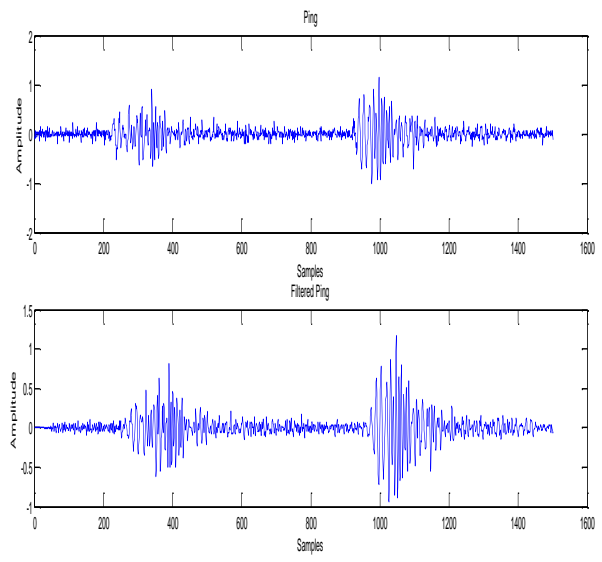

Fig. 6. Noisy and Filtered Ping data

By applying Hilbert transforms to the filtered ping data, the echo envelope is formed and normalized to construct

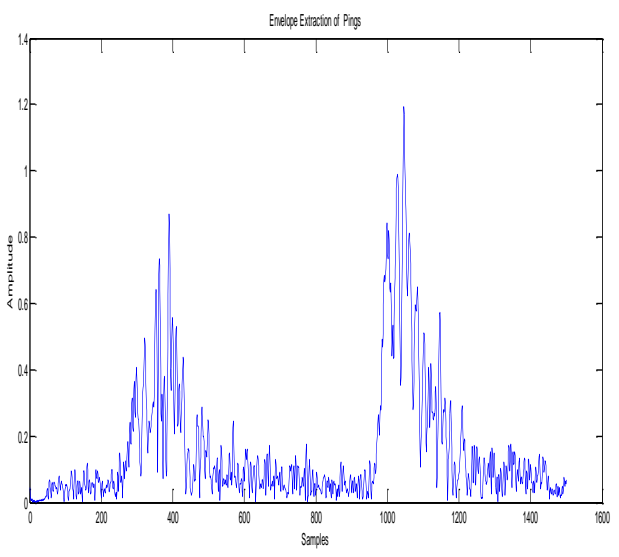

image.

Fig .7. Envelope extraction of ping data

Each echo is designed and the period is manipulated from its altitude calculated from its start-of-echo pick.



Fig.8.Seabed Layer Image 
Gray scale image (Depth vs. Time) is formed using Image processing tools from the echo envelope. Sound travels at about velocity of $1560 \mathrm{~m} / \mathrm{s}$ in sea. For the first ping sound travels to the seabed at the distance of $1560 *(7000-6250) * 20$ microseconds $=23.4 \mathrm{~m}$ Seabed layer Image in gray scale

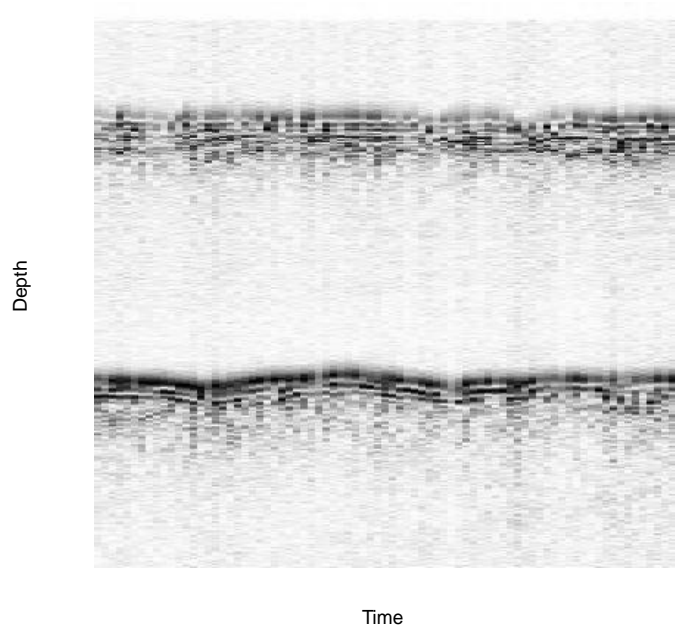

9. Seabed layer in grayscale

\section{VIII.CONCLUSION}

The proposed method for manipulating the bottom impulse response by using the Hilbert transforms that has great potential in sonar signal processing for real sonar data which are in the form of chirps. The underwater classification problem involves finding a classification algorithm that improves the categorization performance over that of normal algorithms. The period of an echo from a single-beam sounder is influenced by the sediment type and is therefore valuable for acoustic seabed classification. Seabed layer is formed for real sonar data and compared with synthetic data. The demonstration of the experimental results can be agreed with the classical method. A complete statistical analysis of the obtained impulse responses for further remains of seabed and comparison of this method with the methods using different transform techniques will be included in the future work.

\section{REFERENCES}

1. Kushal Mukherjee, Student Member, IEEE, Shalabh Gupta, Member, IEEE, Asok Ray, Fellow, IEEE, and Shashi Phoha, Senior Member, IEEE, Symbolic Analysis of Sonar Data for Underwater Target Detection", IEEE JOURNAL OF OCEANIC ENGINEERING, VOL. 36, NO.2,APRIL 2011

2. A Bickers,B Brooke, D A Ryan and P Kennedy" Acoustic Techniques for Seabed Classification", september,2005.

3. Hahn Stefan L., "Hilbert transforms in signal processing", Artech House Inc.,Boston, 1996.

4. A.C.R. Gleason, J.M. Preston, and S.F. Bloomer, "Reproducibility of single-beam acoustic seabed classification," Proc. MTS/IEEE Oceans Conference, Biloxi, USA., 2009..

5. Ellingsen, K. E., Gray, J. S., and Bjørnbom, E. "Acoustic classification of seabed habitats using the QTC VIEWTM system". I CES Journal of Marine Science, 2002

6. Tegowski, J. and Lubniewski, Z. "The use of fractal properties of echo signals for acoustical classification of bottom sediments", 2000

\section{AUTHORS PROFILE}



V.Sunanthini was awarded B.E in EIE from Manonmaniam Sundaranar University and M.E in Applied Electronics from Anna University. She is making a significant original and innovative contribution to the advancement of scholarship and research. Her publications are Parameter Estimation, Modeling and IMC-PID Control of Temperature using Cascade Control Strategy", NCWTRMC, EEC, Chennai. Pg no. 81-88, Sep 2014.

Level control of three interacting system using fuzzy controller, Conference on Technological Innovations in Communication, Control And Automation - TICCA 2017", April 2017

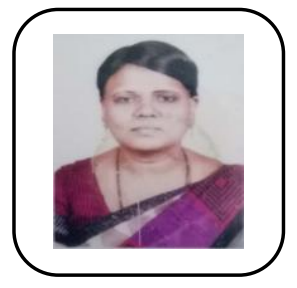

Gunaselvi Manohar was awarded B.E in Instrumentation Technology from MIT ,M.E in Quality Engineering from Anna university and $\mathrm{PhD}$ from Anna University. She got award s of Recipient of "Best Programme Officer Award" from Indian Red Cross Society and Recipient of "Best ISA Student Section Mentor award" from International Society of Automation (ISA)

Chennai. Her Publications are Modeling and Analysis of Horizontal Axis Wind Turbine Using MATLAB/Simulink, International Conference On Technological Innovations In Communication, Control And Automation TICCA 2017”, April 2017,

"Fault Diagnosis in Oil Well Drilling Machine Using Case- Based Reasoning", TIAR 2016,

"An Evolutionary Path For Control Of Air pollution from Road Transport" ,Environment Engineering and Management Journal ,January 2017, Vol.16, No. 1, pp 15-24,

"Study about the Sources of Vehicular Pollution: A Data Mining Approach", International Journal of Applied Engineering Research, ISSN 0973-4562, Vol.10, Issue 27, pp.21780-21784, 2015.(Scopus).

"A Bi-level Clustering Analysis for Studying about the Sources of Vehicular Pollutionin Chennai”, Springer India, Pg no. 229-234, Jan 2015

Evaluation of Polices to Reduce Transportation Pollution using System Dynamics", Journal of Environment Protection Engineering, Vol.40, Dec 2014



"Neural Network
R.Sudha was awarded B.E in ECE from Madras university and M.E in Communication Systems from Anna University. Her Publications are "Neural Network based Level Control in Two Tank Conical Interacting System", IEEE International Conference on Intelligent Systems and Control, ISBN978-14673-4359-6, Pg no.194-196,

Modeling Analysis of Reverse Osmosis Desalination Process", NCWTRMC,EEC, Chennai. Pg no. 27-32, Sep 2014, “

Design And Prototype Implementation Of Indoor Air Quality Monitoring Using Lonworks Technology" 